\title{
Ocorrência de neoplasias em 15 anos de atendimento hospitalar de equídeos
}

\author{
A survey on equine neoplasias over a 15-year period in a veterinary hospital \\ Raquel Yvonne Arantes BACCARIN ${ }^{1}$; Luís Cláudio Lopes Correia da SILVA ${ }^{2}$; Carla Bargi BELLI'; \\ Wilson Roberto FERNANDES ${ }^{1}$; André Luis do Valle De ZOPPA ${ }^{2}$ \\ ${ }^{1}$ Departamento de Clínica Médica da Faculdade de Medicina Veterinária e Zootecnia da \\ Universidade de São Paulo, São Paulo - SP, Brasil \\ ${ }^{2}$ Departamento de Cirurgia da Faculdade de Medicina Veterinária e Zootecnia da \\ Universidade de São Paulo, São Paulo - SP, Brasil
}

\begin{abstract}
Resumo
Apesar de vários estudos fornecerem informações sobre a incidência de neoplasias em equinos, há grande variação na distribuição, em decorrência de diferenças regionais, como clima e população racial. Foram analisados 133 casos de neoplasias dentre os 6669 equídeos atendidos no Hospital Veterinário da Faculdade de Medicina Veterinária e Zootecnia da Universidade de São Paulo, durante um período de 15 anos, representando 2\% do total de atendimentos. A neoplasia mais frequente foi o carcinoma de células escamosas (45\%), diferindo da maioria dos estudos realizados mundialmente. No sistema tegumentar, a neoplasia mais comum foi o melanoma (34,2\%); nos sistemas ocular e urogenital, foi o carcinoma de células escamosas (76,9\% e 40,9\% respectivamente). Em $68 \%$ dos casos foi realizado tratamento cirúrgico, em $10 \%$, tratamento clínico e em $22 \%$, nenhum tipo de tratamento, por opção do proprietário ou indicação de eutanásia. Óbitos por causas relacionadas às neoplasias ocorreram em $14 \%$ dos casos. Os achados sugerem que o carcinoma de células escamosas ocorre mais frequentemente em nosso atendimento hospitalar. Este fato pode estar relacionado à exposição prolongada à luz ultravioleta, cuja quantidade de radiação em regiões tropicais vem aumentando consideravelmente nas últimas décadas.
\end{abstract}

Palavras-chave: Neoplasia. Equino. Sarcoide. Melanoma. Carcinoma de células escamosas.

\begin{abstract}
Although several prior studies have provided information regarding incidence of tumors in horses, there is a wide variation due to regional differences, such as climate and breed population. A number of 133 cases involving tumors was found among the 6669 equides submitted to the Veterinary Hospital (HOVET) of the School of Veterinary Medicine of the University of São Paulo, during a 15 years period, representing $2 \%$ of all records. The most commonly found neoplasm was the squamous cells carcinoma (45\%), different from most of the studies worldwide. The most common neoplasia in the integument system was melanoma $(34,2 \%)$ and in the ocular $(76,9 \%)$ and urogenital systems $(40,9 \%)$ was squamous cells carcinoma. Surgical intervention was recommended in $68 \%$ of the cases, while a clinical approach was chosen in $10 \%$ of them. Twenty two percent of the horses were not treated due to of the owner option or euthanasia indication. Death associated with tumors occurred on $14 \%$ of the animals during the hospitalization period or treatment. The squamous cell carcinoma occurs more often in our veterinary hospital and may be related to prolonged exposure to ultraviolet radiation, whose amount in the tropics has increased considerably in the last decades.
\end{abstract}

Keywords: Neoplasia. Horse. Sarcoid. Melanoma. Squamous cells carcinoma.

\section{Introdução}

Apesar de vários estudos já terem fornecido informações sobre a incidência de neoplasias em equinos, há grande variação em decorrência da metodologia empregada. Incidências de 1 a 3\% foram descritas quando utilizadas populações de cavalos encaminhados para tratamentos cirúrgicos, $11 \%$ quando os cavalos foram examinados em abatedou-

\section{Correspondência para:}

Raquel Yvonne Arantes Baccarin

Departamento de Clínica Médica, Faculdade de Medicina Veterinária e

Zootecnia

Universidade de São Paulo - USP.

Av. Prof. Dr. Orlando Marques de Paiva, 87 - Cidade Universitária CEP: 05508-270, São Paulo/ SP, Brasil.

Fone/Fax: 5511 3091-1287/1283

e-mail: baccarin@usp.br

Recebido: 02/02/2011

Aprovado: 09/11/2011 
ro $^{1}$, chegando a $18 \%$ de todos os materiais analisados por patologistas ${ }^{2}$. Recentemente, Ramos et al. ${ }^{3}$ publicaram que $8,39 \%$ das amostras provenientes de tecido equino enviadas para exame histopatológico são neoplasias.

Além da metodologia empregada, diferenças regionais, como clima e população racial, influenciam na incidência e tipo de neoplasias, porém, a informação em comum na maioria dos levantamentos é o fato das formações cutâneas serem as mais frequentes nos equinos e, entre elas, o sarcoide ser a neoplasia mais comumente encontrada ${ }^{1,2,4,5,6,7,8,9,10}$. De forma geral, os animais mais idosos são os mais acometidos por neoplasias, porém as formas cutâneas e de tecido conectivo são muito comuns em equinos jovens ${ }^{8}$.

Nos levantamentos publicados entre 1950 e 1967 no estado de Minas Gerais (Brasil), não foram identificados casos de sarcoide em equinos, já no estudo conduzido no estado do Rio Grande do Sul (Brasil), observou-se que $37 \%$ do material proveniente de equino enviado para análise tratava-se de sarcoide 3 .

Valentine ${ }^{2}$ observou que o sarcoide e o carcinoma de células escamosas ocorrem mais frequentemente na região oeste dos Estados Unidos da América quando comparado com a região leste. No levantamento realizado por Dugan et al. ${ }^{11}$, envolvendo 14 faculdades de Medicina Veterinária, observou-se aumento da incidência de carcinoma de células escamosas, relacionado com o aumento da média de radiação solar anual, longitude e altitude, e diminuição da latitude.

Alguns tumores têm apresentação clínica característica, como o melanoma e, até mesmo o sarcoide, encorajando o clínico a realizar um diagnóstico presuntivo. Este tipo de diagnóstico pode ser responsável pelas diferenças entre as ocorrências neoplásicas reportadas pelo atendimento hospitalar e laboratório histopatológico de uma mesma instituição. De qualquer forma, o diagnóstico específico de um tumor é importante, par- ticularmente no que diz respeito ao prognóstico, pois existe grande possibilidade de variações ${ }^{12}$.

Em alguns casos a biópsia pode ser contra indicada, como no caso do carcinoma de células escamosas, que pode apresentar crescimento rápido e invasivo após procedimentos diagnósticos ${ }^{10,13}$. A laparoscopia também pode auxiliar no diagnóstico de formações neoplásicas abdominais, possibilitando sua visibilização direta e direcionando a realização de biópsia ${ }^{14,15}$.

Sendo as doenças neoplásicas uma importante causa de morbidade e mortalidade em cavalos $^{10}$, e para que futuramente seja possível comparar nossos dados com estudos similares de outras regiões geográficas, viabilizar projetos de pesquisa envolvendo testes clínicos e, finalmente, investir no desenvolvimento de novos medicamentos junto às indústrias farmacêuticas, o objetivo deste estudo foi determinar a ocorrência e o tipo de neoplasias mais comum em equídeos em nosso atendimento hospitalar.

\section{Material e Método}

O levantamento da casuística foi executado por meio da análise de fichas registro dos equídeos atendidos no Serviço de Clínica Médica de Equinos do Hospital Veterinário da Faculdade de Medicina Veterinária e Zootecnia da Universidade de São Paulo (HOVET - FMVZ - USP), no período de 1996 a 2010. Para análise foram considerados todos os equídeos atendidos nesse período, particularizando-se para aqueles com diagnóstico de neoplasias as características de espécie, raça, idade, sexo, pelagem, localização da lesão e evolução do quadro clínico.

Os dados foram tabulados e a incidência das diferentes neoplasias foi calculada em relação ao número total de casos diagnosticados, e ao número total de neoplasias identificadas em cada sistema. A análise estatística foi realizada com o uso do teste qui-quadrado quando indicada. 


\section{Resultados e Discussão}

Foram atendidos 6669 equídeos com diferentes enfermidades entre os anos de 1996 e 2010 (Tabela 1). Destes animais, 133 apresentavam neoplasias, representando $2 \%$ do atendimento, incidência esta semelhante à relatada na literatura que refere de 1 a $3 \%$ dentre os animas que foram atendidos em Hospitais Veterinários ${ }^{1,16,17}$.

A maioria dos animais portadores de neoplasias era da espécie equina (Equus caballus) (95\%) e do sexo masculino (71\%), refletindo o perfil da população de equídeos atendida neste hospital (Tabela 1). Estatisticamente não houve predileção por faixa etária $(\mathrm{P}>$ $0,05)$, contudo porcentagem maior de animais com neoplasias foi observada em cavalos com idade superior a 11 anos (Tabela 1). Também foi observada porcentagem maior de cavalos das raças Brasileiro de Hipismo e Mangalarga Marchador apresentando neoplasia $(\mathrm{P}<0,05)$ (Tabela 1$)$.

As neoplasias mais comuns em ordem decrescente de frequência, e que representaram $81 \%$ do total de casos, foram carcinoma de células escamosas, sarcoide, melanoma, linfoma e papiloma. Do restante, oito casos (5\%) não puderam ser determinados e os outros 13\% (17 animais) foram diagnosticados como: hemangiossarcoma, condrossarcoma, sarcoma, adenoma, fibrohistiocitoma, seminoma, teratoma, adenocarcinoma, fibrossarcoma, tumor de células da granulosa e plasmocitoma extra-medular. Quanto à localização da lesão, as neoplasias oculares representaram a maioria dos casos (39\%), sendo que o carcinoma de células escamosas foi o principal tipo de neoplasia encontrada. Nos tumores de origem epitelial e de subcutâneo (30\%), o melanoma prevaleceu sobre o carcinoma de células escamosas e sarcoide. Nos tumores do sistema genital (18\%), houve novamente maior ocorrência do carcinoma de células escamosas.

Segundo Knottenbelt ${ }^{10}$ o sistema tegumentar é o principal alvo de assentamento dos quadros neoplásicos em equinos no mundo todo. Apesar dos dados de literatura citarem que o sarcoide é neoplasia que mais atinge os equídeos ${ }^{1,2,5,7,8,10,13,14}$, em nosso levantamento, o carcinoma de células escamosas foi a mais frequentemente encontrada (45\%) (Tabela 2).

O carcinoma de células escamosas, apesar de apresentar incidência variável nos diversos estudos realizados, é um tumor bastante frequente em equí-

Tabela 1 - Caracterização dos equídeos acometidos por neoplasias em relação à espécie, sexo, idade, e raça - São Paulo - 2011

\begin{tabular}{|c|c|c|c|}
\hline & & $\begin{array}{l}\text { Porcentagem } \\
\text { dos casos com } \\
\text { neoplasia (n) }\end{array}$ & $\begin{array}{l}\text { Porcentagem } \\
\text { da população } \\
\text { hospitalar (n) }\end{array}$ \\
\hline \multirow{3}{*}{ Espécie } & Equinos & $95,5(127)$ & $94,8(6323)$ \\
\hline & Muares & $3(4)$ & $3,2(213)$ \\
\hline & Asininos & $1,5(2)$ & $2(133)$ \\
\hline \multirow{2}{*}{ Sexo } & Machos & 71 & 67 \\
\hline & Fêmeas & 29 & 33 \\
\hline \multirow{5}{*}{ Idade } & 0 a 5 anos & 16 & 36,4 \\
\hline & 6 a 10 anos & 35 & 43,5 \\
\hline & 11 a 15 anos & 30 & 15,2 \\
\hline & Acima de 15 anos & 15 & 4,9 \\
\hline & Idade desconhecida & 4 & 0 \\
\hline \multirow{9}{*}{ Raça } & Sem Raça Definida & 20 & 33 \\
\hline & Brasileiro de Hipismo & $18 \mathrm{a}$ & $5 b$ \\
\hline & Mangalarga Paulista & 14 & 22 \\
\hline & Mangalarga Marchador & $14 \mathrm{a}$ & $2 \mathrm{~b}$ \\
\hline & Árabe & 14 & 6 \\
\hline & Puro Sangue Lusitano & 10 & 4 \\
\hline & American Troter & 4 & 10 \\
\hline & Quarto de Milha & 2 & 10 \\
\hline & Outras & 4 & 8 \\
\hline
\end{tabular}

Letras minúsculas distintas na mesma linha representam diferença estatística $(\mathrm{P}<0,05)$

Tabela 2 - Identificação das neoplasias em equinos no período de 15 anos - São Paulo - 2011

\begin{tabular}{ccc}
\hline neoplasia & Número de casos & \% de casos \\
\hline Carcinoma & 59 & 45 \\
Sarcoide & 22 & 16 \\
Melanoma & 19 & 14 \\
Linfoma & 5 & 4 \\
Papiloma & 3 & 2 \\
Outros & 17 & 13 \\
Indeterminados & 8 & 6 \\
\hline Total & 133 & 100 \\
\hline
\end{tabular}


deos $^{2,9,10}$. Trata-se de um tumor maligno de células epidérmicas que tendem a se diferenciar em queratinócitos ${ }^{8,13}$. Existem diversos fatores associados ao seu desenvolvimento, dentre eles a exposição prolongada à luz ultravioleta, despigmentação da pele, ausência ou rarefação de pelos e mais recentemente relacionado à presença do papilomavírus equino tipo $2^{10,17,18,19}$ (Figura 1).

Dentre estes fatores, a radiação ultravioleta tem sido considerada o principal fator carcinogênico associado ao carcinoma de células escamosas, pois atinge o gene supressor de tumor p53, que se encontra mutado nos carcinomas ${ }^{18}$. É fato que, nos últimos 30 anos, a quantidade de radiação ambiental vem aumentando consideravelmente; e em regiões tropicais, onde os equinos são criados a pasto ou em regime de semi-estabulagem, estes animais ficam por tempo mais prolongado à ação da radiação ultravioleta.

Neste levantamento, o carcinoma de células escamosas foi encontrado principalmente no sistema tegumentar (15,8\%), urogenital $(40,9 \%)$ e nos olhos e anexos $(76,9 \%)$. Os locais reportados como sendo os principais alvos do carcinoma são os olhos e anexos, e genitália ${ }^{10,20}$, e, segundo Von Den Top et al..$^{21}$, é o tumor mais comum do sistema urogenital em equinos machos. A presença de esmegma foi reportado como sendo fator etiológico no desenvolvimento do carcinoma de células escamosas nesta região ${ }^{10,17}$, acometendo animais mais velhos e castrados ${ }^{13,20}$ (Tabela 3).

Uma vez que as características de pelagem são consideradas predisponentes para o desenvolvimento do carcinoma cutâneo, algumas raças que possuem coloração clara ou áreas despigmentadas, como Paint Horse e Apaloosa, são mais propensas ${ }^{9}$. Em nosso levantamento, estas raças não atingiram $4 \%$ de animais com neoplasias, porém suas porcentagens frente à população hospitalar atendida no período também foram inferiores a 1\%. Já a raça Puro Sangue Lusitano, que também possui predomínio de coloração clara, apresentou $10 \%$ de animais com neoplasias, sendo que a porcentagem total de Puro Sangue Lusitanos atendidos no período foi $4 \%$.

O sarcoide foi a segunda neoplasia mais diagnosticada, representando em nossos estudos 16\% dos quadros neoplásicos. Em relação à localização, representou $31,6 \%$ dos casos em sistema tegumentar,

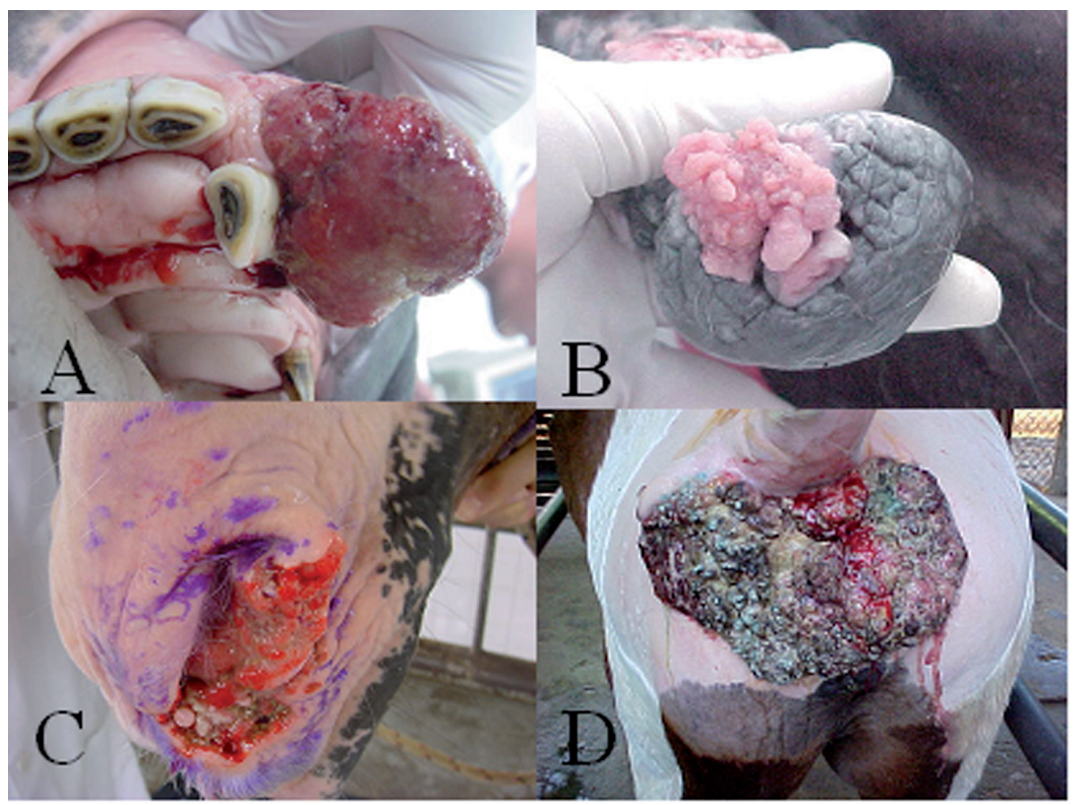

Figura 1 - Carcinoma de células escamosas em região de: A: mucosa oral; B: glande; C: mucosa nasal; D: períneo - São Paulo - 2011 
15,4\% dos localizados em sistema ocular, e 4,5\% dos situados no sistema urogenital, mostrando ter como principal alvo de assentamento o sistema tegumentar, corroborando dados já existentes na literatura ${ }^{2,9,10}(\mathrm{Fi}-$ gura 2 e Tabela 3 ).

O melanoma é outra neoplasia de ocorrência comum em equinos ${ }^{10}$, sendo de incidência variável ${ }^{16}$. Em nossos estudos, o melanoma representou 14\% dos casos de neoplasia, tendo como principal local de assentamento o sistema tegumentar, representando $34,2 \%$ dos casos, seguido pelo sistema urogenital com 27,3\% (Tabela 3 e Figura 3), e pelo sistema ocular com $1,9 \%$. Interessante reportar que um animal acometido por melanoma possuía a pelagem castanha, ou seja, esta neoplasia não é restrita a pelagem tordilha ${ }^{10,12}$.

Tabela 3 - Caracterização das neoplasias estudadas em relação à sua localização, número de casos e classificação - São Paulo - 2011

\begin{tabular}{|c|c|c|c|c|}
\hline Localização & $\begin{array}{l}\text { Numero } \\
\text { de casos }\end{array}$ & $\begin{array}{c}\% \text { do total de } \\
\text { neoplasias }\end{array}$ & $\begin{array}{c}\text { Tipo de } \\
\text { neoplasia }\end{array}$ & $\begin{array}{c}\% \text { do tipo de } \\
\text { neoplasia }\end{array}$ \\
\hline \multirow[t]{4}{*}{ Ocular } & 52 & 39 & Carcinoma & 76,9 \\
\hline & & & Sarcoide & 15,4 \\
\hline & & & Melanoma & 1,9 \\
\hline & & & outros & 5,8 \\
\hline \multirow[t]{4}{*}{ tegumentar } & 40 & 30 & Sarcoide & 31,6 \\
\hline & & & Melanoma & 34,2 \\
\hline & & & Carcinoma & 15,8 \\
\hline & & & outros & 18,4 \\
\hline \multirow[t]{4}{*}{ urogenital } & 24 & 18 & Carcinoma & 40,9 \\
\hline & & & sarcoide & 4,5 \\
\hline & & & Melanoma & 27,3 \\
\hline & & & outros & 27,3 \\
\hline Intra-abdominal & 9 & 7 & & \\
\hline Cavidade Oral/nasal & 5 & 3,8 & & \\
\hline outros & 3 & 2,2 & & \\
\hline TOTAL & 133 & 100 & & \\
\hline
\end{tabular}

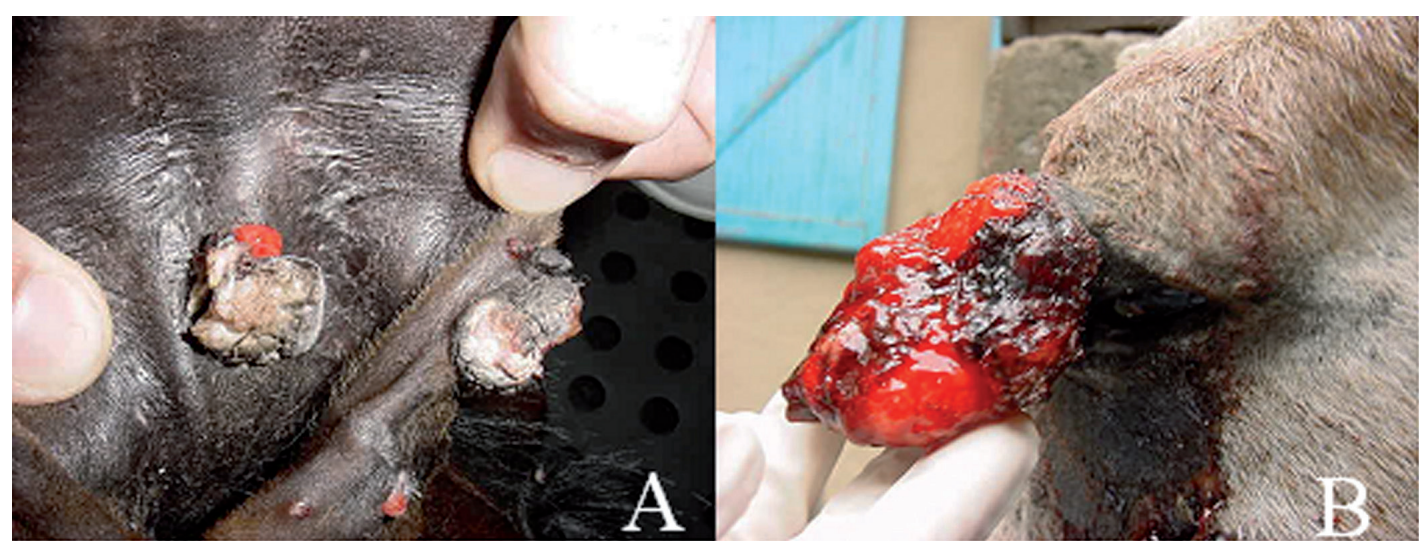

Figura 2 - Sarcoide equino em região de: A: pavilhão auricular; B: pálpebra superior - São Paulo - 2011 


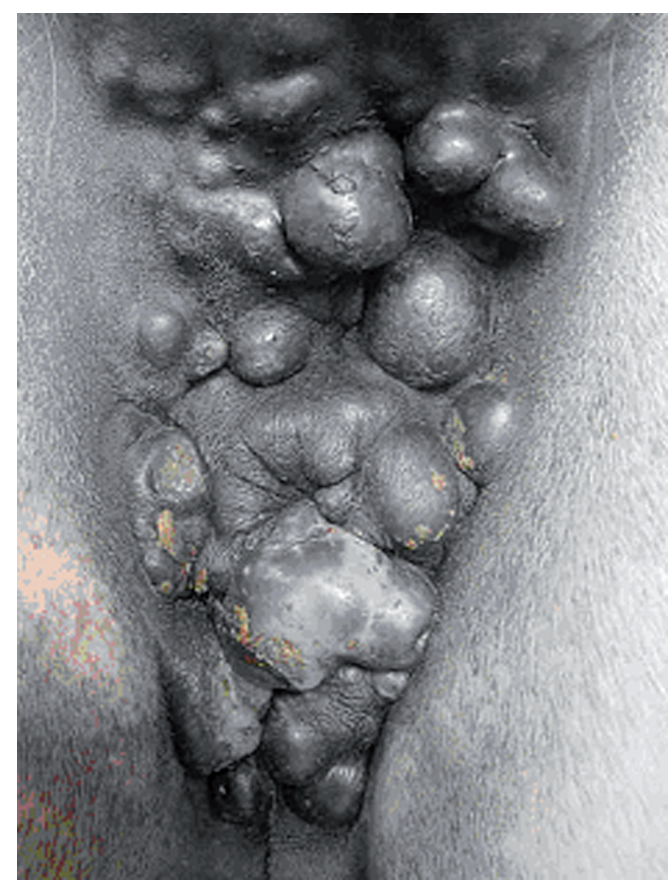

Figura 3 - Melanoma em região anal e base da cauda - São Paulo - 2011

Cotchin ${ }^{1}$ sugere que o aparecimento deste tumor pode estar ligado a anormalidades no metabolismo de melanina nos animais de pelagem tordilha. Normalmente acomete animais tordilhos, porém não exclusivamente ${ }^{9}$. Existem também relatos de maior ocorrência em determinadas raças como o Puro Sangue Árabe, Percheron e Camargue $^{9,22}$, estando provavelmente ligado a raças nas quais a pelagem tordilha é comum. Estes animais, com o passar do tempo, desenvolvem os tumores em algum local do corpo, sendo que os locais tidos como principais alvos são períneo, base da cauda, genitais, glândula parótida e linfonodos ${ }^{10}$.

Neste estudo, 6\% dos casos de neoplasia não recebeu diagnóstico histopatológico, fato relacionado à opção dos proprietários quanto a não realização do exame. $\mathrm{O}$ diagnóstico foi realizado por meio de observações clínicas, portanto não foram computados. Todos os casos com suspeita de neoplasias intra-abdominais foram encaminhados para realização de videolaparoscopia, o que possibilitou tanto diagnóstico, como nos casos de linfoma (Figura 4A), quanto tratamento nos de teratoma testicular (Figura 4B), conforme citado por Silva et al. ${ }^{14}$ e Silva, Zoppa e Hendrickson ${ }^{15}$. Em 68\% dos casos foi realizado tratamento cirúrgico (excisão, criocirurgia e/ou cauterização), em 10\% tratamento clínico e em $22 \%$ não foi feito tratamento devido a não autorização do proprietário ou indicação de eutanásia.

Em relação à evolução dos casos, 86\% receberam alta e $14 \%$ vieram a óbito. Os dados referentes a óbitos incluem animais que receberam indicação médica de eutanásia (57\% dos casos de óbitos), e animais que foram eutanasiados por solicitação dos proprietários.

\section{Conclusões}

Apesar da ocorrência de quadros neoplásicos em nosso atendimento hospitalar ser semelhante
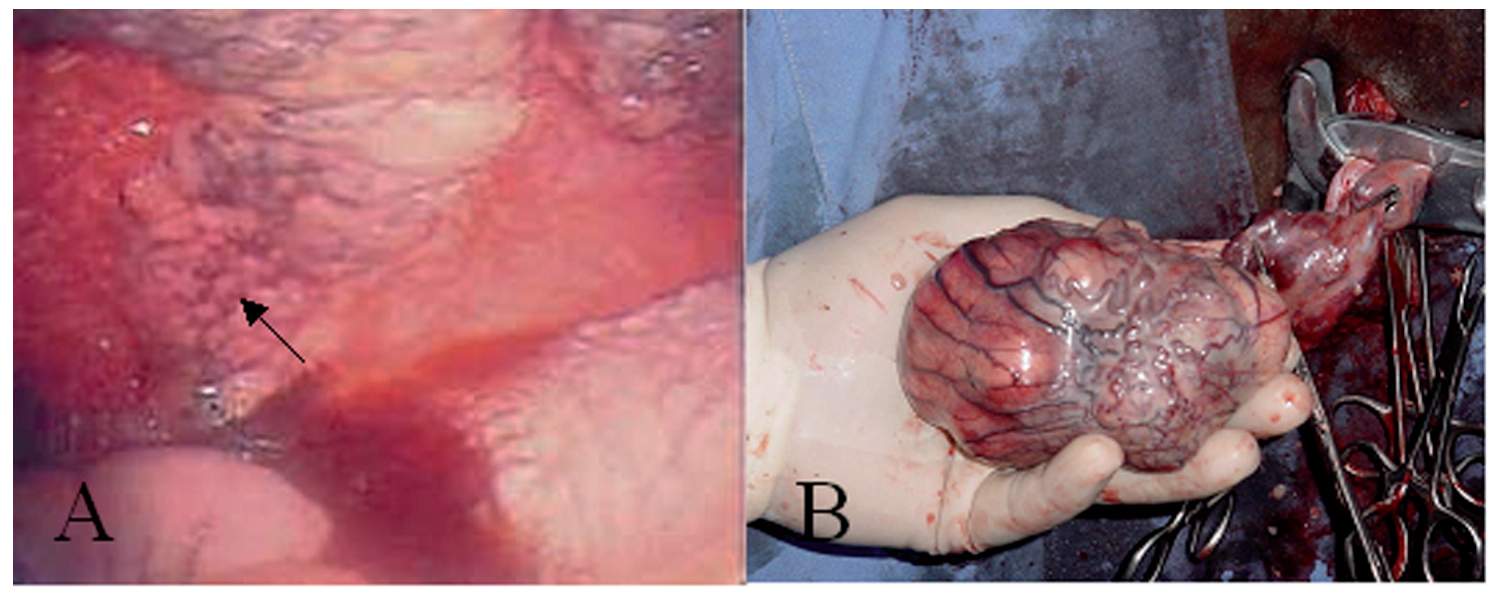

Figura 4 - A: Imagem laparoscópica da superfície peritoneal acometida por linfoma (seta). B: Teratoma testicular - São Paulo - 2011 
ao relatado em outros artigos, o carcinoma de células escamosas, afecção que pode ser relacionada à elevada incidência de radiação ultravioleta,

\section{Referências}

1. COTCHIN, E. A. General Survey of Tumours in the Horse. Equine Veterinary Journal, v. 9, n. 2, p. 16-21, 1977.

2. VALENTINE, B. A. Survey of equine cutaneous neoplasia in the Pacific Northwest. Journal of Veterinary Diagnostic Investigation, v. 18, n. 1, p. 123-126, 2006.

3. RAMOS, A. T.; SOUZA, A. B.; NORTE, D. M.; MONTIEL, F. J. L.; GEVEHR, F. C. Tumores em animais de produção: aspectos comparativos. Ciência Rural, Santa Maria, v. 38, n. 1, p. 148154,2008 .

4. SUNDBERG, J. P.; BURNSTEIN, T.; KIRKHAM, W. W.; ROBINSON, F. R. Neoplasms of equidae. Journal of American Veterinary Medical Association, v. 170, n. 1, p. 150-152, 1977.

5. PASCOE, R. R.; SUMMERS, P. M. Clinical survey of tumours and tumour-like lesions in horses in south east Queensland. Equine Veterinary Journal, v. 13, n. 4, p. 235-239, 1981.

6. MILLER, R. I.; CAMPBELL, R. S. A survey of granulomatous and neoplastic diseases of equine skin in north Queensland. Australian Veterinary Journal, v. 59, n. 2, p. 33-37, 1982.

7. BASTIANELLO, S. S. A survey on neoplasia in domestic species over a 40-year period from 1935 to 1974 in the Republic of South Africa. IV. Tumours occurring in equidae. The Onderstepoort Journal of Veterinary Research, v. 50, n. 2, p. 91-96, 1983.

8. GOLDSCHMIDT, M. H.; HENDRICK, M. J. Tumors of the skin and soft tissues. In: MEUTEN, D. J. Tumors in domestic animals. 4. ed. Ames: Iowa State Press, 2002. p. 45-118.

9. SCOTT, D. W.; MILLER, W. H. Equine dermatology. St Louis: Saunders, 2003

10. KNOTTENBELT, D. C. Neoplastic Conditions. In: DEREK, C.; KNOTTENBELT, B. V. M. Pascoe's principles \& practice of equine dermatology. 2. ed. London: W.B. Saunders, 2009. p. 377-439.

11.DUGAN, S. J.; CURTIS, C. R.; ROBERTS, S. M.; SEVERIN, G. A. Epidemiologic study of ocular/adnexal squamous cell carcinoma in horses. Journal of American Veterinary Medical Association, v. 198, n. 2, p. 251-256, 1991.

12. SCHÖNIGER, S.; SUMMERS, B. A. Equine skin tumours in 20 horses resembling three variants of human melanocytic naevi. Veterinary Dermatology, v. 20, n. 3, p. 165-173, 2009. foi a principal neoplasia diagnosticada em nosso levantamento, diferindo dos dados de literatura mundial.

13.GEMENSKY, A. J.; BEARD, W. L. Ocular Squamous Cell Carcinoma and Sarcoid. In: ROBINSON, N. E. Current therapy in equine medicine. St. Louis: Saunders, 2003. p. 480485.

14.SILVA, L. C. L. C.; FERREIRA, M. A.; BACCARIN, R. Y. A.; FERNANDES, W. R. Aplicação clínica da laparoscopia em equinos. Revista de Educação Continuada do C.R.M.V. S.P., v. 3, n. 3, p. 12-20, 2000.

15.SILVA, L. C. L. C.; ZOPPA, A. L. V.; HENDRICKSON, D. A. Equine Diagnostic Laparoscopy. Journal of Equine Veterinary Science, v. 28, n. 6, p. 247-254, 2008.

16.GOETZ, T. E.; LONG, M. T. Treatment of melanomas in horses. Compendium on Continuing for the Practicing Veterinarian, v. 15, n. 4, p. 608-610, 1993.

17.BURNEY, D.P.; THEISEN, S.K.; SCHMITZ, G.D. Identifying and treating squamous cell carcinoma of horses. The Veterinary Medicine, v. 87, n. 6, p. 588-594, 1992.

18.SANDMEYER, L. S.; PANIZZI, L.; GRAHN, B. H. Diagnostic Ophthalmology. Squamous cell carcinoma. Canadian Veterinary Journal, v. 49, n. 3, p. 309-310, 2008.

19. KNIGHT, C. G.; MUNDAY, J. S.; PETERS, J.; DUNOWSKA, M. Equine Penile Squamous Cell Carcinomas Are Associated With the Presence of Equine Papillomavirus Type 2 DNA Sequences. Veterinary Pathology. 2011. Disponível em: <http://vet. sagepub.com/content/early/2011/01/28/0300985810396516>. Acesso em: 23 set. 2011.

20.PAYNE, R. J.; LEAN, M. S.; GREET, T. R. C. Third eyelid resection as a treatment for suspected squamous cell carcinoma in 24 horses. Veterinary Record, v. 165, n. 25, p. 740-743, 2009.

21.VON DEN TOP, J. G. B.; HEER, N.; KLEIN, W. R.; ENSINK, J. M. Penile and prepucial tumours in the horse: a retrospective study of 144 affected horses. Equine Veterinary Journal, v. 40, n. 6, p. 528-532, 2008.

22.FLEURY, C.; BÉRARD, F.; LEBLOND, A.; FAURE, C.; GANEM, N.; THOMAS, L. The study of cutaneous melanomas in Camargue-type gray-skinned horses (2): epidemiological survey. Pigment Cell Research, v. 13, n. 1, p. 47-51, 2000. 